\title{
The effects of inhaled beclomethasone dipropionate on lung function and histamine responsiveness in recurrently wheezy infants
}

\author{
S M Stick, P R Burton, J B Clough, M Cox, P N LeSouëf, P D Sly
}

\begin{abstract}
Inhaled steroids improve pulmonary function and bronchial responsiveness in older asthmatics. Data from studies using subjective outcome measures to determine the effectiveness of inhaled steroids in infants with recurrent wheezing are equivocal. Therefore, this study tested the hypothesis that beclomethasone dipropionate improves pulmonary function, including bronchial responsiveness to histamine, in recurrently wheezy infants.
\end{abstract}

The study was double blind, placebo controlled lasting nine weeks. After the first baseline week, pulmonary function was measured using the rapid thoracoabdominal compression technique and bronchial responsiveness assessed with a histamine challenge test. Infants were then randomly allocated to receive doses of placebo or beclomethasone dipropionate (100 $\mu \mathrm{g} / \mathrm{puff})$ from metered aerosols. Two puffs of test aerosol were administered twice daily for eight weeks via a large volume spacer fitted with a facemask. Symptoms were recorded daily and pulmonary function and bronchial responsiveness assessed at the end of the treatment period; 50 infants, median age 12 months (range 5 to 18 months), were recruited. Twenty three in the beclomethasone dipropionate group and 15 in the placebo group completed the study and had pairs of pulmonary function measurements. Three were probable treatment failures (one beclomethasone dipropionate, two placebo), three were possible treatment failures (placebo), and others were non-compliant with study protocol. Baseline variables were not significantly different between those infants who completed the study and those who did not. Beclomethasone dipropionate and placebo groups were similar in all respects at baseline.

Lung function and symptoms improved for both groups of infants during the study. Bronchial responsiveness increased significantly in the placebo group but there were no statistically significant differences between groups for any of the other outcome measures. It is concluded that beclomethasone dipropionate (400 $\mu \mathrm{g}$ daily) via a large volume spacer does not significantly improve lung function or symptoms in recurrently wheezy infants but might have a beneficial effect on bronchial responsiveness.

(Arch Dis Child 1995; 73: 327-332)

Keywords: wheezy infants, inhaled steroids, lung function, bronchial responsiveness.

Controversy exists concerning the most effective treatment for recurrently wheezy infants. Although bronchodilators are generally effective in older children with asthma, their effects do not appear to be consistent in infants with airways obstruction. While some authors have described an improvement ${ }^{1}$ others report no effect $^{23}$ or a paradoxical deterioration. ${ }^{4}$ Other studies have investigated selected groups of infants treated with agents used successfully for prophylaxis in older asthmatics. For example, Cogswell and Simpkiss described symptomatic improvement in wheezy infants and preschool children treated with sodium cromoglycate. ${ }^{5}$

More recent studies suggest that inhaled steroids might be effective in infants with wheezing. Inhaled beclomethasone dipropionate reduces wheezing after bronchiolitis ${ }^{6} 7$ and others report improvements in symptoms for wheezy children under 18 months $^{8}$ and 3 years $^{910}$ treated with inhaled budesonide. However, in a study of infants under 18 months of age with recurrent wheeze Van Bever et al failed to show a significant effect of aerosolised budesonide. ${ }^{11}$ All of these studies used subjective symptom scores as a primary outcome measure and none used objective measures of lung function.

We have recently demonstrated using the rapid thoracoabdominal compression technique that wheezy infants have reduced lung function compared with normal controls. ${ }^{12}$ The aim of the present study was therefore to determine whether regular treatment with inhaled beclomethasone dipropionate improves lung function in wheezy infants. Because inhaled steroids improve non-specific bronchial responsiveness in older asthmatics we also determined the effect of treatment with beclomethasone dipropionate on bronchial responsiveness to histamine. ${ }^{13}$

\section{Subjects and methods}

SUBJECTS

Fifty infants were enrolled into the trial. Criteria for entry were age less than 18 months and a history of three discrete episodes of wheezing or persistent wheezing for more than 
four weeks. Infants were excluded if they had an upper respiratory tract infection in the two weeks before the start of the study, if they had significant lung disease other than asthma, or if they were already receiving treatment with corticosteroids (oral or inhaled). Subjects were deemed as treatment failures if they were prescribed any asthma medication in addition to that being used before the start of the study, other than bronchodilators.

\section{PROTOCOL}

The study was a randomised, double blind, placebo controlled design lasting nine weeks. Infants attended the respiratory laboratory at Princess Margaret Hospital for Children on four occasions. During the first visit details of the subject's previous medical history were obtained and physical examination performed. The parents were issued with a simple diary to record daytime and nocturnal symptoms of cough and wheeze on a scale from 0 (no symptoms) to 3 (severe symptoms) and the use of medications for the duration of the study. The maximum possible daily symptom score was 12 indicating severe daytime and night time symptoms. A modified American Thoracic Society questionnaire was administered to determine the smoking habits and presence of atopy in primary relatives.

The first week of the study was used to establish the baseline symptom score. At the second visit each infant had lung function and response to inhaled histamine measured. Each child was then provided with a numbered metered aerosol inhaler corresponding to their study number containing beclomethasone dipropionate $(100 \mu \mathrm{g}$ per actuation) or placebo. The metered aerosol inhalers were prepared in advance by Glaxo (Australia), randomised in blocks of four, and numbered from one to 50. Parents were instructed to administer two single puffs from the metered aerosol using a Volumatic spacer fitted with a silastic Laerdal facemask (Laerdal Medical, Stavanger, Norway) twice a day for eight weeks. They were advised to allow the infant to take between $5-10$ breaths after each puff of aerosol. The third visit was four weeks later, midway through the treatment period. During this visit the metered aerosol was replaced and a clinical assessment performed. At the fourth and final appointment, lung function measurements were repeated as for the second visit. Two weeks after the second and third visits contact was made by telephone to inquire about any problems and to encourage compliance with treatment and symptom recording.

\section{MEASUREMENT OF LUNG FUNCTION AND} HISTAMINE RESPONSIVENESS

Studies were performed either in the morning or afternoon and the infants attended at the same time for each of their bronchial challenges.

Respiratory function was assessed using the rapid thoracoabdominal compression technique. ${ }^{14}$ To produce forced expiration, an inflatable plastic jacket was wrapped around the ribcage and abdomen. At end inspiration the jacket was rapidly inflated and the resultant flow measured at functional residual capacity (FRC). Jacket pressure was gradually increased over a series of forced expirations until maximum flow at FRC (VmaxFRC) was obtained. ${ }^{14}$

Flow was measured using a Fleisch No 1 pneumotachograph (PK Morgan Ltd, Chatham, England), a Validyne DP45 pressure transducer and a Validyne CD19 amplifier (Validyne Co, CA, USA). The infant breathed through a putty facemask attached to the pneumotachograph. Jacket pressure was measured using a Gould 23d pressure transducer (Gould Inc, Dayton, Ohio, USA) and Nihon-Kohden AP-621G carrier amplifier (Nihon-Kohden Corporation, Tokyo). All signals were digitised with a 12 bit analogdigital converter and the digitised signals were sampled and recorded at a frequency of $50 \mathrm{~Hz}$ using Anadat (v 5.0: RHT-Infodat, Montreal, Canada) data acquisition software on a personal computer. The software was used to integrate the digitised flow signal with respect to time to give volume. Oxygen saturation was measured continuously throughout each study (Biox III pulse oximeter, Ohmeda, Boulder, Colorado, USA).

Infants were studied while sleeping after receiving chloral hydrate $(80 \mathrm{mg} / \mathrm{kg})$. The minimum jacket pressure required to produce VmaxFRC was then established. This pressure was then used for all subsequent forced expirations. Aerosols of saline and histamine were delivered directly to the facemask using an Intertech/Inspiron nebuliser (Intertech Resources Inc, Lincolnshire, IL, USA) driven by compressed air at a constant flow of 8 litres/minute and inhaled during one minute of tidal breathing.

Baseline VmaxFRC was established as the mean of five forced expirations after the saline nebulisation. The bronchial challenge was performed using doubling concentrations of histamine from $0 \cdot 125 \mathrm{~g} / 1$ to a maximum concentration of $8 \mathrm{~g} / 1 .{ }^{15}$ Doses were delivered every five minutes and respiratory function was assessed after each dose with a minimum of five forced expirations being performed. The challenge ceased when a response was recorded or the maximum concentration of histamine was reached. A response was defined as a fall in mean VmaxFRC of $40 \%$ or more from baseline and the provocation concentration for a fall in VmaxFRC (PC40) was derived from the plot of log concentration of histamine against V́maxFRC by linear interpolation between the last two points on the semilogarithmic dose response graph.

Written, informed consent was obtained from the parents of all subjects and the study was approved by the hospital's ethics committee.

\section{STATISTICAL ANALYSIS}

Lung function is expressed as raw VmaxFRC values and as \% predicted VmaxFRC based on length. ${ }^{16}$ Changes in lung function and PC40 
were compared between groups using unpaired Student's $t$ tests. Other data were compared using Student's unpaired $t$ tests for normally distributed data and Mann-Whitney $\mathrm{U}$ tests for non-normally distributed data. Symptom scores are expressed as the mean score per week and were compared using analysis of variance for repeated measures.

Treatment failure was defined as 'probable' if additional asthma treatment was required after two weeks or more of treatment with test aerosol or 'possible' if additional treatment was required after less than two weeks' treatment.

\section{Results}

All 50 infants had baseline lung function measured. Twenty three infants in the beclomethasone dipropionate group and 15 in the placebo group completed the eight week treatment period and had pulmonary function measurements repeated. Twenty three infants ( 13 beclomethasone dipropionate, 10 placebo) completed two histamine challenges and 31 ( 20 beclomethasone dipropionate, 11 placebo) infants had complete diary records.

The ages, lengths, gender distribution, lung function, histamine responsiveness, and symptom scores at baseline for the initial 50 infants and those 38 in the final analysis were similar in the beclomethasone dipropionate and control groups (table 1). The median duration of symptoms before the study was seven months (range 1 to 16 months) and was similar in each group.

There were no significant differences within the initial and final groups regarding a primary family history of asthma or smoke exposure. Seventy eight per cent of the beclomethasone dipropionate group had a family history of asthma compared with $81 \%$ of the placebo group; $57 \%$ of infants in the beclomethasone dipropionate group were exposed to environmental tobacco smoke at home compared with $75 \%$ of the placebo group.

Three infants from the placebo group and one from the beclomethasone dipropionate group were withdrawn from the study because

Table 1 Baseline details of infants studied (values are mean (SD) except where otherwise stated)

\begin{tabular}{lcc}
\hline & $\begin{array}{l}\text { Beclomethasone dipropionate } \\
(n=25)\end{array}$ & $\begin{array}{c}\text { Placebo } \\
(n=25)\end{array}$ \\
\hline Median (range) age (months) & $12 \cdot 0(5 \cdot 0-18 \cdot 0)$ & $13 \cdot 0(6 \cdot 0-17 \cdot 0)$ \\
M/F & $17 / 8(\mathrm{r})$ & $19 / 6$ \\
Height (cm) & $75 \cdot 9(4 \cdot 6)$ & $74 \cdot 9(4 \cdot 6)$ \\
VmaxFRC (m1/s) & $125 \cdot 9(71 \cdot 2)$ & $100 \cdot 6(52 \cdot 8)$ \\
Symptoms/week & $25 \cdot 0(19 \cdot 0)$ & $21 \cdot 0(16 \cdot 0)$ \\
Geometric mean PC40 $(\mathrm{g} / \mathrm{l})$ & $1 \cdot 75$ & $1 \cdot 83$ \\
Failed to complete & 2 & 10 \\
\hline
\end{tabular}

they failed to comply with the study protocol and did not attend for follow up appointments.

We were unable to obtain follow up pulmonary function measurements for one child from the placebo group due to technical difficulties. However, the weekly symptom scores from this individual were included in the final analysis.

One infant from the placebo group was given oral prednisolone for treatment of a middle ear effusion before surgery for grommet insertion and was therefore withdrawn.

There were three probable treatment failures. Two infants from the placebo group were treated with inhaled steroids: one after 17 days and the other after seven weeks' treatment with test aerosol. One infant from the beclomethasone dipropionate group was admitted to hospital two weeks after starting treatment with test aerosol and was prescribed a combination of oral and inhaled steroids.

Three infants from the placebo group were possible treatment failures. Two were prescribed inhaled steroids after less than one week of treatment with test aerosol; another was prescribed sodium cromoglycate after 12 days of treatment. The infants who failed to complete the study did not differ significantly from those who completed the study with regard to any of the baseline variables. We attempted to assess compliance with treatment instructions by weighing aerosol canisters at visits 3 and 4. Parents were not informed in advance of our intention to do so.

For the group as a whole, the median percentage of prescribed doses actuated was $94 \%$ (range $24 \%$ to $136 \%$ ) and the mean percentage of prescribed doses actuated for the study period was similar in the beclomethasone dipropionate $(97 \%)$ and placebo $(89 \%)$ groups. We believe that some parents performed a test actuation before administering the aerosol resulting in high apparent compliance for some subjects. However, despite the limitations of this assessment we consider that the results reflect efforts (such as maintaining regular and frequent contact with parents) that are likely to have resulted in acceptable overall compliance. There was no relation between apparent compliance and any of the outcome measures (whole group and beclomethasone dipropionate group analysed separately).

VmaxFRC improved in both beclomethasone dipropionate and placebo groups during the study period (table 2; fig 1). Changes in VmaxFRC were not significantly different between the groups when expressed as; change in $\mathrm{ml} / \mathrm{s}$ from baseline VmaxFRC, \% change VmaxFRC from baseline, change in per cent

Table 2 Changes in lung function (values are mean (95\% confidence interval) except for raw PC40 which is geometric mean (95\% confidence interval))

\begin{tabular}{|c|c|c|c|c|c|c|}
\hline & \multicolumn{3}{|c|}{ Beclomethasone dipropionate } & \multicolumn{3}{|l|}{ Placebo } \\
\hline & Baseline & End & Difference† & Baseline & End & Difference $†$ \\
\hline $\begin{array}{l}V \max F R C(\mathrm{ml} / \mathrm{s}) \\
\text { VmaxFRC }(\%\end{array}$ & $126.4(96 \cdot 0$ to $156 \cdot 8)$ & $152 \cdot 6(110 \cdot 2$ to $195 \cdot 0)$ & $26 \cdot 2(-0.7$ to $52 \cdot 3)$ & $97 \cdot 4(66.9$ to $127 \cdot 9)$ & $146 \cdot 8(110 \cdot 8$ to $182 \cdot 8)$ & $49 \cdot 4(15 \cdot 2$ to $83 \cdot 7)$ \\
\hline $\begin{array}{l}\text { predicted) } \\
\text { PC40 (g/l) }\end{array}$ & $\begin{array}{c}50.9(39.9 \text { to } 62.0) \\
1.34(0.9 \text { to } 4.0)\end{array}$ & $\begin{array}{c}57 \cdot 4(43.4 \text { to } 71 \cdot 4) \\
2 \cdot 15(1.16 \text { to } 4 \cdot 61)\end{array}$ & $\begin{array}{l}6.5(-2.9 \text { to } 15.9) \\
0.68(-0.16 \text { to } 1.51)^{\star}\end{array}$ & $\begin{array}{c}40.4(29.3 \text { to } 51.5) \\
3.03(0.8 \text { to } 6.8)\end{array}$ & $\begin{array}{l}57.4(44.7 \text { to } 70.1) \\
0.98(0.33 \text { to } 2.89)\end{array}$ & $\begin{array}{l}17.0(3.2 \text { to } 30.8) \\
-1.64(-2.25 \text { to }-1.02)\end{array}$ \\
\hline
\end{tabular}

${ }^{\star}$ Change from baseline approaching statistical significance $(p=0.06)$ and significantly different to placebo $(p<0.01)$.

†PC40 difference expressed as doubling concentrations. 


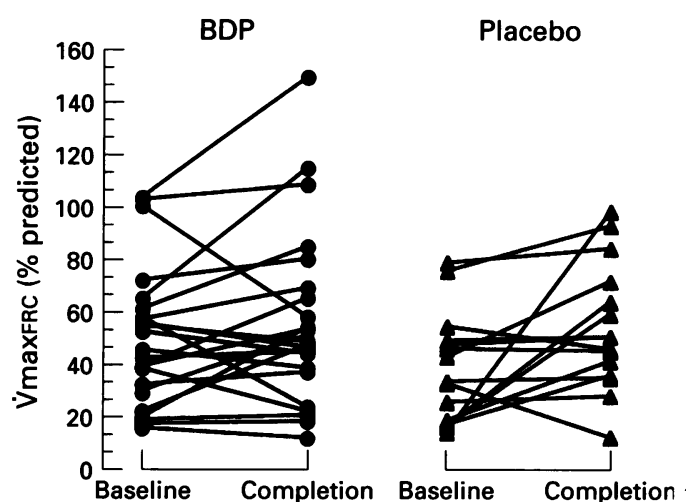

Figure 1 Individual changes in \% predicted VmaxFRC; $B D P=$ beclomethasone dipropionate.

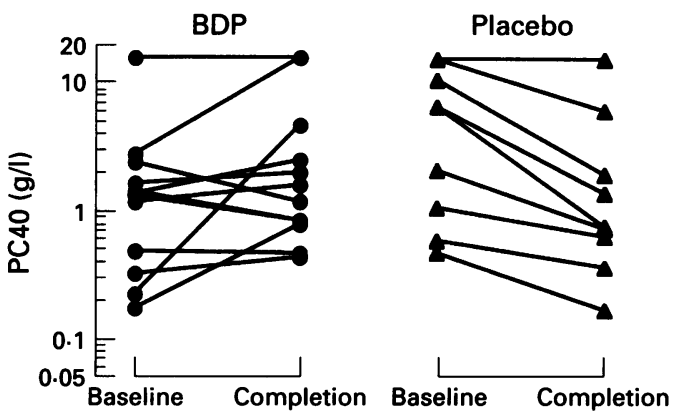

Figure 2 Individual changes in bronchial responsiveness; $B D P=$ beclomethasone dipropionate.

predicted VmaxFRC or \% change in \% predicted VimaxFRC.

The outcome with regard to bronchial responsiveness was significantly different in the beclomethasone dipropionate group compared with the placebo group $(\mathrm{p}<0.01)$ (table 2) despite the observation that there was a statistically non-significant increase in PC40 in the beclomethasone dipropionate group. The geometric mean PC40 fell significantly during the treatment period in the placebo group $(-1.64$ doubling concentrations) compared with the slight increase in PC40 observed in the beclomethasone dipropionate group $(0.68$ doubling concentrations) (table 2; fig 2).

The median weekly symptom score was similar in the beclomethasone dipropionate group and placebo group at baseline. The scores improved for each group throughout the treatment period but the degree of improvement was not significantly greater in the beclomethasone dipropionate group compared with the placebo group (fig 3). Furthermore, the mean proportion of symptom-free days in the beclomethasone dipropionate group (31\%) was similar to that in the placebo group (37\%). There were no specific guidelines given to the parents regarding use of bronchodilators but

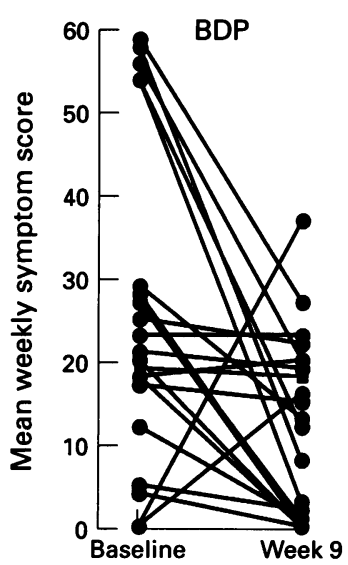

Placebo

Figure 3 Individual changes in mean weekly symptom scores; $B D P=$ beclomethasone dipropionate.

their use was similar in both groups and tended to decline during the study.

The responses to beclomethasone dipropionate compared with placebo were no different in those infants with a family history of asthma or smoking.

\section{Discussion}

As far as we are aware this is the first study to evaluate the effect of inhaled steroids on objective measures of lung function in recurrently wheezy infants. Infants treated with beclomethasone dipropionate inhaled through a facemask from a large volume spacer did not have a significant improvement in lung function compared with infants treated with placebo. Despite overall improvements in lung function for infants in both treatment groups there was still evidence of significant airway obstruction at the end of the study with mean $\%$ predicted values for VmaxFRC of $57 \%$ in both the beclomethasone dipropionate and placebo groups. This suggests that if reversible airways narrowing was the cause of the low values of VmaxFRC there was still potential for substantial improvement.

Although infants in the placebo group had a significant increase in bronchial responsiveness during the study period compared with those who received beclomethasone dipropionate this may not be clinically relevant. A previous study suggests that increased bronchial responsiveness is not an important pathophysiological mechanism in infants with recurrent wheezing. ${ }^{12}$ Furthermore, in the present study increases in the level of bronchial responsiveness were not associated with worsening of lung function or symptom scores.

As with lung function, symptoms improved in both the beclomethasone dipropionate and

Table 3 Details of other studies of inhaled steroids in infants

\begin{tabular}{|c|c|c|c|c|c|}
\hline Study & Mean age (range) & Drug & Device & Duration & Dose given twice a day \\
\hline $\begin{array}{l}\text { Effective } \\
\text { Connett } e t a l^{10} \\
\text { Bisgaard } e t a l^{9} \\
\text { Noble } e t \text { al } \\
\text { Ineffective }\end{array}$ & $\begin{array}{l}1 \cdot 7(1-3) \text { Years } \\
24(11-36) \text { Months } \\
11(4-18) \text { Months }\end{array}$ & $\begin{array}{l}\text { BUD } \\
\text { BUD } \\
\text { BUD }\end{array}$ & $\begin{array}{l}\text { Metered aerosol+spacer } \\
\text { Metered aerosol + spacer } \\
\text { Metered aerosol + spacer }\end{array}$ & $\begin{array}{l}6 \text { Months } \\
3 \text { Months } \\
6 \text { Weeks }\end{array}$ & $\begin{array}{l}2-400 \mu g \\
400 \mu g \\
150 \mu g\end{array}$ \\
\hline $\begin{array}{l}\text { Stick et al } 12 \\
\text { Van Bever et al }{ }^{11}\end{array}$ & $\begin{array}{l}12 \text { (5-18) Months } \\
10(3-17) \text { Months }\end{array}$ & $\begin{array}{l}\text { BDP } \\
\text { BUD }\end{array}$ & $\begin{array}{l}\text { Metered aerosol+spacer } \\
\text { Nebuliser }\end{array}$ & $\begin{array}{l}2 \text { Months } \\
1 \text { Month }\end{array}$ & $\begin{array}{l}200 \mu \mathrm{g} \\
0.5 \mathrm{mg}\end{array}$ \\
\hline
\end{tabular}

$\mathrm{BUD}=$ budesonide; $\mathrm{BDP}=$ beclomethasone dipropionate. 
placebo group during the course of the study but treatment with beclomethasone dipropionate did not result in a significantly greater improvement compared with placebo. Results from other studies of inhaled steroids in young children that have used symptom scores as an outcome variable are equivocal. Only Noble et $a l^{8}$ and Van Bever et al ${ }^{11}$ have published studies in comparable children as young as those in the present study and the results from these studies are contradictory. Furthermore, in the study by Noble et al only half of the original study population were included in the final analysis and it is doubtful that the small improvements in symptom scores described are of clinical significance when considered in relation to their standard errors. Other authors who report a positive treatment effect studied older children who are also more likely to respond to other forms of inhaled asthma medication. ${ }^{35}$ The results of these studies are summarised in table 3.

There are a number of theoretical explanations related to methodology for the lack of response in VmaxFRC to beclomethasone dipropionate in our study.

(1) Inadequate dose: the actuated dose that we used is effective in older children and adults with asthma and is considerably larger than that used routinely in adults when considered in relation to body (and hence lung) size. ${ }^{17}$

(2) Inadequate delivery: this seems unlikely. Other studies have demonstrated the effectiveness of metered aerosols with holding chambers as a means of delivering aerosol to infants and young children. ${ }^{17-19} \mathrm{We}$ instructed parents how to use the device so that drug delivery would be maximised. ${ }^{17}$ Furthermore, this technique is likely to be more efficient for delivering an aerosol than using a nebuliser. ${ }^{17} 20$

(3) Inadequate power to detect a clinically significant response: clinically significant improvements in the \% predicted VmaxFRC and PC40 are greater than $40 \%$ and two doubling concentrations respectively. ${ }^{15}$ That being the case, although it is relatively small, this study does have adequate power to demonstrate clearly that the true difference between groups with respect to changes in VmaxFRC is unlikely to be large enough to be clinically relevant. In fact, assuming a bayesian prior density that is uniform on the principal scale of analysis, it may be estimated ${ }^{21}$ that the posterior probability that the true difference between groups with respect to changes in \% predicted VmaxFRC (beclomethasone dipropionate minus placebo) is as large as, or larger than, $+40 \%$ (rather than $-10.5 \%$ as observed) is less than $10^{-6}$ and the posterior probability that beclomethasone dipropionate offers any advantage at all (difference in change $>0 \%$ ) is only $10 \%$. On the other hand, the study not only suggests that the change in PC40 differs significantly between the two treatment groups, but also suggests that there is a reasonably high posterior probability $(71 \%)$ that the true difference is of a magnitude in excess of two doubling doses.

(4) Differential drop out: because of the design of the study, it was impossible to carry out an analysis based upon 'intention to treat'.
However, although this is unfortunate, it is unlikely that this would have led to a qualitative change in our principal inferences. With respect to the change in \% predicted

VmaxFRC, given that the placebo group exhibited a markedly (although non-significantly) more beneficial change than the beclomethasone dipropionate group, it would have to be postulated that there were either extreme negative changes in the placebo drop outs or extreme positive changes in the beclomethasone dipropionate drop outs in order to conceal an important real benefit of beclomethasone dipropionate. Given that there were no important baseline differences between the drop outs and those infants that completed the study, it would seem very unlikely that any putative changes in the drop outs would be large enough and sufficiently discordant with the changes in those who did not drop outs to support such a hypothesis. Similarly, large discordancies in the change in PC40 in drop outs would have to be postulated in order to support the hypothesis that there was really no difference between the two groups and that the apparent beneficial effect of beclomethasone dipropionate arose solely as a consequence of the differential non-response.

(5) Inadequate duration of treatment: objective data from adults with asthma that includes assessments of pulmonary function and bronchial responsiveness suggest a plateau in the response to inhaled steroids at approximately eight weeks. ${ }^{13}$ Other studies in wheezy young children have reported functional improvement after shorter periods of treatment than in our study. ${ }^{68}$ Therefore, assuming that the low forced expiratory flows observed in recurrently wheezy infants result from similar pathophysiological mechanisms to those in older children and adults with asthma, the duration of treatment in our study should have been sufficient to demonstrate a beneficial effect of beclomethasone dipropionate on pulmonary function. However, recent studies suggest that the pathophysiological mechanisms responsible for recurrent wheezing in infants may be different from those involved in asthma later in life. The natural history of recurrent wheezing in the majority of infants is to resolve by school age 22 and there is evidence that the airways of some infants are relatively small, ${ }^{12} 24$ which might predispose them to wheezing when inflammation or oedema occurs secondary to some environmental trigger. Previous studies have suggested that treatment with inhaled steroids reduces the frequency of wheezing episodes after bronchiolitis. ${ }^{6}$ Therefore, although beclomethasone dipropionate does not result in overall improvement in lung function or symptoms in the short term, it might be useful for reducing the frequency of wheezy episodes resulting from triggers such as viral respiratory infections and exposure to cigarette smoke, when treatment is given over a longer period. This protective effect might be mediated through stabilisation of bronchial responsiveness as observed during the present study. However, considering the potential for inhaled 
steroids to cause side effects, the natural tendency for recurrent wheezing in infancy to resolve and the likelihood that any potential benefit is marginal, we do not recommend the routine use of inhaled steroids in recurrently wheezing infants under the age of 18 months. However, treatment might be justified in those wheezy infants who continue to have severe recurent symptoms or reduced pulmonary function without spontaneous improvement.

We would like to thank Glaxo (Australia) for financial support Dr Stick was supported by a NH and MRC scholarship.

1 Radford M. Effect of salbutamol in infants with wheezy bronchitis. Arch Dis Child 1975; 50: 535-8.

2 Silverman M. Bronchodilators for wheezy infants. Arch Dis Child 1984; 59: 84-7.

3 Lenney W, Milner A. At what age do bronchodilator drugs work? Arch Dis Child 1978; 53: 532-5.

4 O'Callaghan C, Milner A, Swarbrick A. Paradoxical deterioration of lung function after nebulized salbutamol in wheezy infants. Lancet 1986; ii: 1424-5.

5 Cogswell J, Simpkiss $M$. Nebulised sodium cromoglycate in recurrently wheezy preschool children. Arch Dis Child 1985; 60: 736-8.

6 Maayan C, Itchaki T, Bar-Yishay E, Gross S, Tal A Godfrey $S$. The functional response of infants with persistent wheezing to nebulized beclomethasone dipropionate. Pediatr Pulmonol 1986; 2: 9-14.

7 Carlsen K, Leegaard J, Larsen S, Ørstavik I. Nebulised beclomethasone dipropionate in recurrent obstructive episodes after acute bronchiolitis. Arch Dis Child 1988; 63 . 1428-33.

8 Noble V, Ruggins N, Milner A. Inhaled budesonide for chronic wheezing under 18 months of age. Arch Dis Child 1992; 67: 285-8.

9 Bisgaard H, Munck S, Nielsen J, Petersen W, Ohlsson S. Inhaled budesonide for treatment of recurrent wheezing in early childhood. Lancet 1990; 336: 649-51.
10 Connett G, Warde C, Wooler E, Lenney W. Use of budesonide in severe asthmatics aged 1-3 years. Arch Dis Child 1993; 69: 351-5.

11 Van Bever H, Schuddinck L, Wojciechowski M, Stevens W. Aerosolized budesonide in asthmatic infants: a double blind study. Pediatr Pulmomol 1990; 9: 177-80.

12 Stick S, Arnott J, Landau LI, Turner D, S SY, LeSouëf P. Bronchial responsiveness and lung function in recurrently Bronchial responsiveness and lung function in recurren
wheezy infants. Am Rev Respir Dis 1991; 144: 1012-5.

13 Kraan J, Koëter G, Mark TWVD, et al. Dosage and time effects of inhaled budesonide on bronchial hyperreactivity. Am Rev Respir Dis 1988; 137: 44-8.

14 Taussig L, Landau L, Godfrey S, Arad I. Determinants of forced expiratory flow in newborn infants. $\mathcal{F}$ Appl Physiol 1982; 53: 1270-7.

15 Stick $S$, Turner D, LeSouëf $P$. Lung function and bronchial challenges in infants: repeatability of histamine and comparison with methacholine challenges. Pediatr Pulmonol 1993; 16: 177-83.

16 Tepper R, Morgan W, Cota K, Wright A, Taussig L, GHMA Pediatricians. Physiologic growth and development of the lung during the first year of life. Am Rev Respir Dis 1986; 134: 513-9.

17 Everard M, Clark A, Milner A. Drug delivery from holding chambers with attached facemask. Arch Dis Child 1992; 67: $580-5$.

18 O'Callaghan C, Milner A, Swarbrick A. Spacer device with facemask attachment from giving bronchodilators to infants with asthma. BMF 1989; 248: $160-1$

19 Connor W, Dolovich M, Frame R, Newhouse M. Reliable salbutamol administration in 6 to 36 month children by means of a metered dose inhaler and Aerochamber with facemask. Pediatr Pulmonol 1989; 6: 263-7.

20 Everard M, Clark A, Milner A. Drug delivery from jet nebulisers. Arch Dis Child 1992; 67: 586-91.

21 Burton PR. Helping doctors to draw appropriate inferences from the analysis of medical studies. Stat Med 1994; 13: 1699-714.

22 Foucard T, Sjoberg O. Prospective 12 year follow-up study of children with wheezy bronchitis. Acta Paediatr Scand 1984; 73: 577-83.

23 Park E. Preschool wheezing and prognosis at 10. Arch Dis Child 1986; 61: 642-6.

24 Martinez F, Morgan W, Wright A, Holberg C, Taussig L, GHMA Pediatricians. Diminished lung function as a predisposing factor for wheezing respiratory illness in infants. N Engl f Med 1988; 319: 1112-7. 